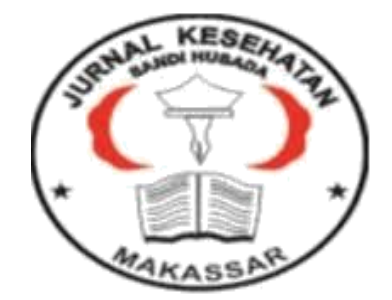

\author{
Jurnal Ilmiah Kesehatan Sandi Husada \\ hhttps://akper-sandikarsa.e-journal.id/JIKSH \\ Volume 9, Nomor 2, Desember 2020, pp 971-975 \\ p-ISSN: 2354-6093 dan e-ISSN: 2654-4563 \\ DOI: $10.35816 /$ jiskh.v10i2.449
}

\title{
Hubungan antara motivasi belajar dengan prestasi belajar mahasiswa
}

Relationship between Learning Motivation and Student Achievement

Yuriatson Yuriatson ${ }^{1}$, A. Syamsinar Asmi ${ }^{2}$

12 Keperawatan Politeknik Sandi Karsa

\section{Artikel info}

Artikel history:

Received; Agustus 2020

Revised: September 2020

Accepted; Oktober 2020

\begin{abstract}
.
Background; improving the quality of human resources is a must for the world, especially in the era of globalization which demands the readiness of every nation to compete freely. Method; Analytical descriptive with a cross sectional study design where the researcher made observations or instantaneous variable measurements, meaning that the subject was observed only once and explored simultaneously using a questionnaire measuring instrument. Through population determination, sampling and sampling, data collection, data processing and data analysis. Result; The analysis shows that 28 respondents (84.8\%) have good motivation, 1 respondent (3.0\%) is moderate, and there is no lack of achievement. Meanwhile, 4 respondents (12.1\%) had less motivation to learn. Conclusion; motivation has an important function in learning, because motivation will determine the intensity of the student's learning efforts.
\end{abstract}

\begin{abstract}
Abstrak
Latar belakang; peningkatan kualitas sumber daya manusia sudah merupakan suatu keharusan bagi dunia apalagi pada era globalisasi yang menuntut kesiapan setiap bangsa untuk bersaing secara bebas. Metode; deskriptif analitik dengan rancangan cross sectional study dimana peneliti melakukan observasi atau pengukuran variabel sesaat artinya subyek diobservasi satu kali saja dan dieksplorasikan secara bersamaan dengan menggunakan alat ukur kuesioner. Melalui penentuan populasi, sampel dan sampling, pengumpulan data, pengolahan data dan analisa data. Hasil; analisis menunjukkan bahwa motivasi baik sebanyak 28 responden $(84,8 \%)$ memiliki prestasi baik, 1 responden (3,0\%) sedang, dan prestasi kurang tidak ada. Sedangkan untuk responden motivasi belajar kurang sebanyak 4 responden $(12,1 \%)$ memiliki prestasi baik. Kesimpulan; motivasi mempunyai fungsi yang penting dalam belajar, karena motivasi akan menentukan intensitas usaha belajar yang dilakukan mahasiswa.
\end{abstract}

\section{Keywords:}

Motivation to learn;

Student achievements;
Coresponden author:

Email: yuriatson@akper-sandikarsa.ac.id

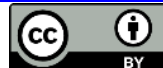

artikel dengan akses terbuka dibawah lisensi CC BY -4.0 


\section{Pendahuluan}

Pada era globalisasi hanya bangsa-bangsa yang berkualitas tinggi yang mampu bersaing atau berkompetisi di pasar bebas. Dalam hubungannya dengan budaya kompetisi tersebut, bidang pendidikan memegang peranan yang sangat penting dan strategis karena merupakan salah satu wahana untuk menciptakan kualitas sumber daya manusia, oleh karena itu sudah semestinya kalau pembangunan sektor pendidikan menjadi prioritas utama yang harus dilakukan pemerintah(Yusuf, 1993).

Inovasi dan upaya meningkatkan mutu pendidikan di asia telah lama dilakukan. Berbagai inovasi dan program pendidikan juga telah dilaksanakan, antara lain penyempurnaan kurikulum, pengadaan buku ajar, peningkatan mutu dosen dan tenaga kependidikan lainnya melalui pelatihan dan peningkatan kualitas pendidikan mereka, peningkatan manajemen pendidikan dan pengadaan fasilitas lainnya (Tomo, 2019).

Permasalahan yang diteliti motivasi belajar merupakan hal yang sangat penting, karena motivasi akan mampu mendorong perilaku mahasiswa (Students behavior), untuk bergairah, bersemangat dan rasa senang dalam belajar, sehingga pada akhirnya akan mampu memperoleh prestasi belajar yang lebih baik. Tujuan mengetahui motivasi, tingkat prestasi dan hubungan antara motivasi belajar dengan prestasi belajar mahasiswa keperawatan.

\section{Metode}

Jenis penelitian deskriptif analitik dengan pendekatan cross sectional yaitu survey analitik dengan metode potong melintang (cross sectional), dimana peneliti melakukan observasi dan pengukuran variabel hanya satu kali pada saat bersamaan. Variabel independen dan dependen dieksplorasikan secara bersamaan dengan menggunakan alat ukur kuesioner, sedangkan data yang diperoleh dianalisis secara deskriptif dan analisis hubungan antara variabel independen dengan variabel dependennya. Penelitian dilaksanakan pada bulan Juni-Agustus 2020 di salah satu Perguruan Tinggi Swasta di Kota Makassar.

Sampel semua mahasiswa keperawatan yang memenuhi kreteria inklusi berjumlah 33 orang dengan teknik pusposive sampling. Pengumpulan data merupakan hasil pencatatan peneliti, baik yang berupa fakta maupun angka. Data yang digunakan dalam penelitian ini adalah data primer dan data sekunder. Data di analisis secara univariat dan bivariat uji Chi-square menggunakan program komputer SPSS (Statistical Product and ServiceSolution). 


\section{Hasil Dan Pembahasan}

Tabel 1 Analsisi Motivasi belajar dengan prestasi belajar mahasiswa

\begin{tabular}{|c|c|c|c|c|c|c|c|}
\hline \multirow{3}{*}{ No } & \multirow{3}{*}{ Motivasi belajar } & \multicolumn{6}{|c|}{ Prestasi Belajar } \\
\hline & & \multicolumn{2}{|c|}{ Baik } & \multicolumn{2}{|c|}{ Sedang } & \multicolumn{2}{|c|}{ Total } \\
\hline & & $\sum$ & $\%$ & $\sum$ & $\%$ & $\sum$ & $\%$ \\
\hline 1 & Baik & 28 & 84,8 & 1 & 3,0 & 29 & 87,8 \\
\hline \multirow[t]{2}{*}{2} & Kurang & 4 & 12,1 & 0 & 0 & 4 & 12,1 \\
\hline & Total & 32 & 96,9 & 1 & 3,0 & 33 & 100 \\
\hline
\end{tabular}

Sumber : Data Primer 2020

Berdasarkan analisis data menunjukkan bahwa dari jumlah 33 responden, responden dengan motivasi baik sebanyak 28 responden $(84,8 \%)$ memiliki prestasi baik, 1 responden $(3,0 \%)$ sedang, dan prestasi kurang tidak ada. Sedangkan untuk responden motivasi belajar kurang sebanyak 4 responden $(12,1 \%)$ memiliki prestasi baik, sedangkan prestasi belajar sedang dan kurang tidak ada.

Motivasi mempunyai fungsi yang penting dalam belajar, karena motivasi akan menentukan intensitas usaha belajar yang dilakukan mahasiswa. Hawley dalam (Yusuf, 1993) menyatakan bahwa para mahasiswa yang memiliki motivasi tinggi, belajarnya lebih baik dibandingkan dengan mahasiswa yang motivasi belajarnya rendah. Prestasi belajar merupakan hasil yang telah dicapai dari suatu proses belajar yang telah dilakukan, sehingga untuk mengetahui sesuatu pekerjaan berhasil atau tidak diperlukan suatu pengukuran. "Pengukuran adalah proses penentuan luas/kuantitas sesuatu" Dalam kegiatan pengukuran hasil belajar, mahasiswa dihadapkan pada tugas, pertanyaan atau persoalan yang harus dipecahkan/dijawab (Nurkancana \& Sumartana, 1986).

Sejalan dengan hasil penelitian Sholeh (Sholeh, 2013) bahwa terdapat hubungan minat dan motivasi dengan prestasi belajar. Berdasarkan hasil penelitian Handari (Handari, 2010) bahwa terdapat hubungan antara motivasi belajar dan persepsi tentang figur perawat dengan prestasi akademik mahasiswa. Dari hasil uji spearmen untuk motivasi menjadi perawat dengan prestasi belajar didapatkan hasil $p$ value 0,007 dengan coefisien corelasi 0,284. Bahwa terdapat hubungan antara motivasi menjadi perawat dengan prestasi belajar pada matakuliah keperawatan dasar di FIK Unissula Semarang(Zaliman, 2017). Menurut hasil penelitian Firdaus (Firdaus \& Imallah, 2017) bahwa mahasiswa yang memiliki motivasi tinggi sebanyak $79(55.6 \%)$ dan mahasiswa yang memiliki indeks prestasi belajar cume laude sebanyak 70 (49.3\%), analisis uji kendall's tau menunjukkan bahwa ada hubungan motivasi belajar dengan prestasi belajar mahasiswa semester II program studi ilmu Keperawatan universitas 'Aisyiyah Yogyakarta. Menurut Suprapto (Suprapto et al., 2019) prestasi akademik merupakan prestasi belajar terakhir yang dicapai siswa dalam kurun waktu tertentu dimana prestasi akademik siswa biasanya dinyatakan dalam bentuk angka atau symbol.

(Umboh et al., 2017) berpendapat bahwa motivasi belajar adalah keseluruhan daya penggerak di dalam diri seseorang yang mampu menimbulkan semangat atau kegairahan belajar terdapat hubungan antara motivasi belajar dengan prestasi akademik pada mahasiswa Program Studi Ilmu Keperawatan Fakultas Kedokteran Universitas Sam Ratulangi manado. Model konseptual kunci dalam literatur motivasi, yang mempromosikan pentingnya menciptakan peluang untuk penguasaan pembelajaran, melibatkan nilai tugas, menghasilkan konteks pembelajaran yang optimal, dan menciptakan mekanisme untuk mengatasi dan mengelola pemicu kecemasan yang tak terelakkan. pengalaman belajar yang dihadapi mahasiswa kedokteran(Henning et al., 2011). Selain gaya belajar mereka, tingkat kesadaran dan pemahaman emosi mereka 
sendiri yang lebih tinggi memiliki dampak positif pada prestasi akademik siswa. Kecerdasan emosional yang lebih tinggi dapat mengarahkan siswa untuk mengejar minat mereka dengan lebih bersemangat dan berpikir lebih luas tentang mata pelajaran yang diminati, yang dapat menjadi faktor penjelas untuk kinerja akademis yang lebih tinggi dalam kelompok mahasiswa keperawatan ini(Fernandez et al., 2012).

Konsep diri yang lebih tinggi ditemukan berhubungan langsung dengan prestasi akademis yang lebih tinggi. Kecemasan tes dan motivasi intrinsik ditemukan menjadi mediator yang signifikan dalam hubungan antara konsep diri dan prestasi akademik. Selain itu, motivasi intrinsik secara signifikan memoderasi pengaruh negatif kecemasan tes terhadap prestasi akademik(Khalaila, 2015). Menurut pendapat Rose(Rose, 2011) bahwa sekolah keperawatan di seluruh dunia, termasuk program keperawatan gelar associate (ADN), terus mendapat tantangan dari masalah retensi dan rekrutmen. Banyak upaya telah dilakukan untuk mengatasi berbagai masalah kompleks yang dihadapi pendidik perawat untuk meningkatkan retensi dan perekrutan siswa dalam program keperawatan. Untungnya, pendaftaran di banyak program keperawatan terus meningkat, karena tantangan ekonomi di Amerika Serikat terus tidak tergoyahkan. Shahram(Shahram Vahedi,etall, 2012) mengungkapkan prestasi akademik kelompok motivasi kuantitas rendah lebih rendah dibandingkan kelompok lainnya. Perempuan memiliki motivasi otonom yang lebih tinggi dibandingkan dengan laki-laki. Keterampilan komunikasi dan motivasi belajar diukur.

Mahasiswa kedokteran yang mengevaluasi hubungan gaya belajar dengan kepuasan mahasiswa dan prestasi akademik. Diperlukan lebih banyak penelitian dengan kelompok yang lebih besar untuk menggeneralisasi hasil kami. Beberapa gaya belajar mungkin berhubungan dengan kepuasan dan pencapaian dalam beberapa metode pengajaran (Gurpinar et al., 2010). Kelompok intervensi menunjukkan keterampilan komunikasi dan motivasi belajar yang lebih tinggi secara signifikan setelah intervensi daripada kelompok kontrol. Temuan menunjukkan bahwa peer review merupakan metode pembelajaran yang efektif bagi mahasiswa keperawatan untuk meningkatkan keterampilan komunikasi dan motivasi belajar (Yoo \& Chae, 2011).

\section{Simpulan Dan Saran}

Terdapat hubungan motivasi belajar dengan prestasi belajar mahasiswa. Motivasi memiliki peran yang sangat penting dalam menentukan prsetasi belajar seseorang, karena motivasi akan menentukan intensitas usaha belajar yang dilakukan mahasiswa. Hasil penelitian dapat memberikan pengetahuan bahwa motivasi belajar itu sangat penting untuk meningkatkan prestasi belajar.

\section{Daftar Rujukan}

Fernandez, R., Salamonson, Y., \& Griffiths, R. (2012). Emotional intelligence as a predictor of academic performance in first-year accelerated graduate entry nursing students. Journal of Clinical Nursing, 21(23-24), 3485-3492. https://doi.org/10.1111/j.13652702.2012.04199.x

Firdaus, N., \& Imallah, R. N. (2017). Hubungan Motivasi Belajar Dengan Prestasi Belajar Mahasiswa Semester Ii Program Studi Ilmu Keperawatan Universitas 'Aisyiyah Yogyakarta. Universitas' Aisyiyah Yogyakarta.

Gurpinar, E., Alimoglu, M. K., Mamakli, S., \& Aktekin, M. (2010). Can learning style predict student satisfaction with different instruction methods and academic achievement 
in medical education? Advances in Physiology Education, 34(4), 192-196. https://doi.org/10.1152/advan.00075.2010

Handari, M. (2010). Hubungan antara motivasi belajar dan persepsi tentang figur perawat dengan prestasi akademik mahasiswa program studi DIII Keperawatan STIKES Wira Husada Yogyakarta. UNS (Sebelas Maret University).

Henning, M. A., Krägeloh, C. U., Hawken, S. J., Doherty, I., Zhao, Y., \& Shulruf, B. (2011). Motivation to Learn, Quality of Life and Estimated Academic Achievement: Medical Students Studying in New Zealand. Medical Science Educator, 21(2), 142-150. https://doi.org/10.1007/BF03341611

Khalaila, R. (2015). The relationship between academic self-concept, intrinsic motivation, test anxiety, and academic achievement among nursing students: Mediating and moderating effects. Nurse Education Today, 35(3), 432-438. https://doi.org/https://doi.org/10.1016/j.nedt.2014.11.001

Nurkancana, W., \& Sumartana, P. P. N. (1986). Evaluasi pendidikan. Surabaya: Usaha Nasional.

Rose, S. (2011). Academic success of nursing students: Does motivation matter? Teaching and Learning in Nursing, 6(4), 181-184. https://doi.org/https://doi.org/10.1016/j.teln.2011.05.004

Shahram Vahedi *, Khalil Esmaeel poor, Vahid Zamanzadeh, A. A. zade. (2012). The nursing students' motivational profile and its relationship to their academic achievement:A person-oriented approach TT - نيمر خهاى انكيزش تحصيلى دانشجويان يرستارى و ارتباط آن بإيشرفت تحصبلى :رويكرد فرد- محور. In IJNV (Vol. 1, Issue 1, pp. 36-46). http://ijnv.ir/article-1-66en.html

Sholeh, K. I. (2013). Hubungan Antara Minat Menjadi Perawat Dan Motivasi Belajar Dengan Prestasi Belajar Pada Mahasiswa Akper Rspad Gatot Soebroto.

Suprapto, S., Malik, A., \& Yuriatson, Y. (2019). Hubungan Motivasi Menjadi Perawat dengan Prestasi Belajar Mahasiswa Akademi Keperawatan Sandi Karsa. Jurnal Ilmiah Kesehatan Sandi Husada, 10(2 SE-Articles). https://doi.org/10.35816/jiskh.v10i2.101

Tomo, J. (2019). Hubungan antara sikap, motivasi, disiplin belajar dan prestasi belajar mahasiswa D-II PGSD prajabatan FKIP Universitas Pattimura. SKRIPSI Mahasiswa $U M$.

Umboh, E., Kepel, B., \& Hamel, R. (2017). Hubungan Antara Motivasi Belajar Dengan Prestasi Akademik Pada Mahasiswa Program Studi Ilmu Keperawatan Fakultas Kedokteran Universitas Sam Ratulangi Manado. Jurnal Keperawatan UNSRAT, 5(1), 108275.

Yoo, M. S., \& Chae, S. M. (2011). Effects of peer review on communication skills and learning motivation among nursing students. Journal of Nursing Education, 50(4), 230-233.

Yusuf, S. (1993). Dasar-dasar Pembinaan Kemampuan Proses Belajar Mengajar. Bandung. Andira.

Zaliman, Z. (2017). Hubungan Motivasi Menjadi Perawat Dengan Prestasi Belajar Pada Matakuliah Keperawatan Dasar Di Fakultas Ilmu Keperawatan Unissula Semarang. Fakultas Ilmu Keperawatan UNISSULA. 